\title{
Magnitude, determinants and impact of under-reporting of energy intake in a cohort study in Greece
}

\author{
Charalambos Gnardellis, Chariklia Boulou and Antonia Trichopoulou* \\ Department of Nutrition and Biochemistry, National School of Public Health, Athens, Greece
}

Submitied 4 December 1997: Accepted 8 April 1998

\begin{abstract}
Abstroct
Objectives: To investigate the frequency and the determinants of under-reporting in a semi-quantitative food frequency questionnaire used in the Greek segment of the European Prospective Study on Nutrition, Cancer and Health (EPIC study).

Design: A food frequency questionnaire was completed by 9262 adult men and women. The questions included in this questionnaire covered the average intake of approximately 150 food items and beverages over 1 year. Evaluation of underreporting was conducted on an individual basis taking into account the expected daily variation of nutritional intakes during the time period of recording. Individuals whose energy intake was lower than $1.14^{*} \mathrm{BMR}$ (basal metabolic rate) were defined as under-reporters.

Setting: Urban and rural population of Greece.

Results: The data indicated underestimation of energy intake by $11.8 \%$ of individuals enrolled. Results from a logistic regression model indicated that body mass index (BMI), gender, age and educational level were significant predictors of underreporting. The proportion of overweight participants (BMI $>30$ ) who tend to under-report energy intake was more than twice that of normal-weight individuals. Men were significantly more prone to under-reporting compared to women, while low education individuals under-report more often than others. Exclusion of underreporters generated, as expected, mean nutrient values that were significantly higher (by about $6 \%$ ) than those derived from the total number of participants. When the nutrient values were energy-adjusted, however, or were expressed as percentages of energy intake for macronutrients or as nutrient densities for micronutrients, the emerging differences were minimal and generally statistically not significant.

Conclusions: Under-reporting does exist and it is more extensive among men, those with low education levels and the overweight participants. Adjustment for energy intake minimizes the bias generated by under-reporting with respect to particular nutrients and their association with various disease outcomes in the cohort.
\end{abstract}

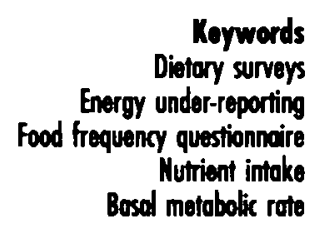

Over the last few years researchers have gained substantial experience on the evaluation of results derived from large-scale nutritional studies. A major methodological issue has been the ascertainment of energy intake data, since most of these studies were based on the assumption that the reported energy intake was umbiased without being able to establish this by using independent non-nutritional methods.

The doubly-labelled water technique for the measurement of total energy expenditure in freeliving persons, enabled scientists to conduct validation studies comparing energy expenditure to energy intake ${ }^{1,2}$. However, the fact that this method is very expensive and technically difficult to employ as a routine process makes it impossible to use in wide ranging nutritional epidemiological studies. Investigators have suggested ${ }^{3-5}$ the determination of cut-off points to represent the limits of energy needs for free-living persons. Such values have been stated as multiples of the basic metabolic rate and the lower cut-offs indicate the lowest level of energy expenditures for weight-stable individuals. Therefore, assuming that there is no weight loss, estimates of energy intake lower than these cut-off points could be 'suspected' of underestimated energy intake.

Goldberg et al $^{3}$ determined the lowest level of energy expenditure of individuals based on germane principles of energy physiology. In their approach, data from doubly-labelled water and whole body calorimetry studies on a large number of healthy individuals were used. The cut-off point was first determined as 1.35. This is defined as the lowest likely long-term habitual intake for healthy sedentary adults. However, habitual intake is very difficult to assess, even when dietary intake is recorded over long periods of time (e.g. by food frequency questionnaires or diet history 
records). Thus, in order to establish valid energy intake records during the actual period of measurement, a second cut-off point was determined. The formula to calculate this took into consideration the daily variation of nutrition during the time period of recording. The latter cut-off point is more 'liberal' from the first one, and its calculation depends on the sample size and the number of days for which intake is recorded. This value results in more specific rejection of intake values, deemed as biased estimates of true nutritional intake.

The objective of this study is to investigate the extent and the determinants of under-reporting in a large cohort study in which dietary intakes were ascertained through a food frequency questionnaire. The lowest critical value for energy intake was determined using the equations proposed by Goldberg et al. ${ }^{3}$

\section{Subjects and methods}

In the context of the Greek component of the European Prospective Study on Nutrition, Cancer and Health (EPIC study), a semi-quantitative food frequency questionnaire was completed by 9262 adult men and women aged from 30 to 82 years old. These study participants were volunteers from throughout Greece, who have all signed an informed consent form. The EPIC is a multi-country prospective study on nutrition and other lifestyle and environmental factors in relation to the incidence of, and mortality from, cancer and other diseases. Approximately 350,000 Europeans, all volunteers, from nine European countries will eventually have participated in the EPIC study. For all these individuals there is a detailed recording of nutritional habits, information concerning their lifestyle and family history, while anthropometric measurements and blood samples are also collected ${ }^{6,7}$.

The semi-quantitative food frequency questionnaire was developed from previous experience from several case-control studies conducted in the population of Athens $^{8}$ and from dietary ascertainment methodology obtained in the large cohort studies conducted in the USA ${ }^{9,10}$. The repeatability and the validity of the questionnaire was evaluated in the pilot phase of the study ${ }^{1,12}$. The questions included in this questionnaire regarded the average intake of approximately 150 food items and beverages over 1 year. For a number of these items (about 20), there were separate questions concerning seasonal differences in consumption. Portions were estimated by 'natural' units (e.g. one egg) or standard quantities (e.g. one teaspoon), where possible or on the basis of pictures. The analysis of the nutritional data was carried out using a food composition database adapted to accommodate the characteristics of the Greek diet ${ }^{13}$.

The anthropometric data of the volunteers in this study, specifically the weight and height, were used for the estimation of their basal metabolic rate (BMR). The BMR was estimated using the Schofield equations $^{14}$.

The values of BMR derived from these equations, were subsequently used for the calculation of the EI/BMR ratio (where EI is the daily energy intake). This value is essentially the reported daily energy intake of an individual expressed in 'metabolic units', that reflect physical activity level. The cut-off limits for the physiologically plausible energy intake of a weight-stable individual were calculated from the equations developed by Goldberg et $a l^{3}$ These equations are based on an expected mean total energy expenditure value (TEE/BMR), which for an average sedentary individual is estimated to be $1.55^{15}$. EI/BMR should be greater than or equal to TEE/BMR. The lower cut-off limit is then defined as the lower 95\% confidence limit of the expected TEE/BMR, taking into account inter-individual variation in TEE/BMR values. The calculations also allow for the day-to-day variation in individual energy intake, the error in predicting BMR, the number of days on which the intake is based and the number of individuals in the group. Based on these assumptions Goldberg et al. came up with the following equation to calculate the limits of a physiologically plausible EI/BMR value:

$$
\begin{aligned}
& \mathrm{EI} / \mathrm{BMR} \geq \mathrm{TEE} / \mathrm{BMR} \times \exp \left[-2 \times \frac{(S / 100)}{\sqrt{n}}\right] \\
& \text { where } S=\sqrt{\left[\left(\mathrm{CV}_{\mathrm{Iw}}^{2} / k\right)+C V_{\mathrm{B}}^{2}+\mathrm{CV}_{\mathrm{p}}^{2}\right]}
\end{aligned}
$$

and $\mathrm{CV}_{\mathrm{Iw}}=$ within-individual coefficient of variation for energy intake; $\mathrm{CV}_{\mathrm{B}}=$ coefficient of variation of measured or predicted BMR; $\mathrm{CV}_{\mathrm{P}}=$ coefficient of variation for TEE/BMR; $n=$ number of individuals for which intake is examined (if recording is undergone on an individual basis then $n=1$ ); and $k=$ number of days for which intake is recorded (for FFQs $k$ approaches infinity and so $\mathrm{CV}_{\mathrm{I} w}^{2} / k=0$ ).

The TEE/BMR ratio for an average sedentary individual is estimated to be $1.55^{15}$. The mean withinindividual $\mathrm{CV}$ for energy intake, has been found in various studies to be approximately $23 \%{ }^{16}$. The $\mathrm{CV}$ for estimated BMR has been determined to be $8 \%{ }^{14}$ while the CV for the TEE/BMR ratio is $12.5 \%{ }^{15}$.

Thus in the context of our study, for a physiologically plausible EI/BMR value the following assumptions apply:

$$
\mathrm{CV}_{\mathrm{Iw}}^{2}=0, \quad \mathrm{CV}_{\mathrm{B}}^{2}=(8)^{2}, \quad \mathrm{CV}_{\mathrm{p}}^{2}=(12.5)^{2}
$$


Table 1 Mean values for age, BMI, energy intake, BMR and EI/BMR ratio according to gender of participants

\begin{tabular}{|c|c|c|c|c|c|c|}
\hline & \multicolumn{2}{|c|}{$\begin{array}{c}\text { Men } \\
(n=3884)\end{array}$} & \multicolumn{2}{|c|}{$\begin{array}{l}\text { Women } \\
(n=5378)\end{array}$} & \multicolumn{2}{|c|}{$\begin{array}{c}\text { Total } \\
(n=9262)\end{array}$} \\
\hline & Mean & SD & Mean & SD & Mean & SD \\
\hline $\begin{array}{l}\text { Age } \\
\text { BMl } \\
\text { Energy (kcal) } \\
\text { Energy (MJ) } \\
\text { BMR (MJ) } \\
\text { El/BMR }\end{array}$ & $\begin{array}{c}52.1 \\
27.8 \\
2779.0 \\
11.6 \\
7.2 \\
1.62\end{array}$ & $\begin{array}{r}12.5 \\
3.7 \\
859.0 \\
3.6 \\
0.9 \\
0.48\end{array}$ & $\begin{array}{r}52.3 \\
27.8 \\
2328.0 \\
9.7 \\
5.7 \\
1.72\end{array}$ & $\begin{array}{r}12.1 \\
5.2 \\
728.0 \\
3.0 \\
0.5 \\
0.53\end{array}$ & $\begin{array}{r}52.2 \\
27.8 \\
2517.0 \\
10.5 \\
6.3 \\
1.67\end{array}$ & $\begin{array}{r}12.3 \\
4.5 \\
816.0 \\
3.4 \\
1.0 \\
0.51\end{array}$ \\
\hline
\end{tabular}

$$
\mathrm{EI} / \mathrm{BMR} \geq 1.55 \times \exp \left[-2 \times \frac{(S / 100)}{\sqrt{n}}\right]
$$

$$
\text { where } S=\sqrt{\left[(8)^{2}+(12.5)^{2}\right]}
$$

so $\mathrm{EI} / \mathrm{BMR} \geq 1.14$ provided that evaluation is conducted on an individual basis $(n=1)$. Individuals whose energy intake was below this cut-off point were defined as under-reporters.

For a study sample of about 10,000 individuals the under-reporting cut-off point, under the conditions of our study, is calculated as $1.54^{3}$.

\section{Statistical methods}

Statistical analysis was made using the SPSS statistical package (version 7.5, SPSS Inc., Chicago). Predictors of under-reporting were assessed by modelling the data through logistic regression. A model was developed using as independent variables age, sex, BMR and educational level of the participants, whereas the dependent variable was under-reporting status (yes/ no). Between-group comparisons for nutrient means were conducted through $t$-test.

\section{Results}

Individuals for the evaluation of under-reporting were those who declared that no specific diet was used at the time of recording. This implies, to a large extent, that the participants were not on a diet for weight loss. The study base consisted of 5378 (58.1\%) females and $3884(41.9 \%)$ males. The average age for each gender was approximately 52 years, and the average BMI for each gender was $27.8 \mathrm{~kg} \mathrm{~m}^{-2}$. The mean daily energy intake assessed from the analysis of the nutritional data was $2779 \mathrm{kcal}(11.6 \mathrm{MJ})$ for men and $2328 \mathrm{kcal}$ $(9.7 \mathrm{MJ})$ for women. Also, the mean EI/BMR ratio is 1.67 ranging from 0.44 to 6.37 . This mean value is greater than the lower cut-off limit of the expected mean $\mathrm{TEE} / \mathrm{BMR}=1.54$ for the total of the sample individuals ${ }^{3}$ (Table 1).

Individuals who under-report their energy intake represent $11.8 \%$ of the participants. This percentage varies by gender (men 13.5\%, women $10.5 \%$ ) and BMI value (Table 2 ).

Results from the logistic regression modelling indicate that BMI, gender and educational level are significant predictors of under-reporting. BMI appears to have a strong influence on the probability that someone reports implausibly low energy intakes. A person with BMI over $30 \mathrm{~kg} \mathrm{~m}^{-2}$ is more than twice as likely to under-report energy intake compared to an individual with a BMI equal or less of $25 \mathrm{~kg} \mathrm{~m}^{-2}$, after adjusting for sex, age and educational level. Males are significantly more prone to under-reporting compared to females, while illiterate people appear to under-report more often than others. Finally, age is a significant predictor for under-reporting after adjustment for other variables (Table 3 ).

Table 4 refers to mean daily intake values of various nutrients for men and women, before and after exclusion of under-reporters. As expected, all values increase by approximately $6 \%$ when data from underreporters are excluded.

Finally, Tables 5 and 6 refer to mean daily energy intake values derived from macronutrients as a percentage of the total, and mean daily micronutrient densities $\left(\mathrm{mg} \mathrm{MJ}^{-1}\right)$, respectively. Differences in the

\begin{tabular}{|c|c|c|c|c|c|c|c|c|}
\hline & \multicolumn{2}{|c|}{$B M I \leq 25$} & \multicolumn{2}{|c|}{$25<\mathrm{BMI} \leq 30$} & \multicolumn{2}{|c|}{$\mathrm{BMI}>\mathbf{3 0}$} & \multicolumn{2}{|c|}{ Total } \\
\hline & $n$ & $\%$ & $n$ & $\%$ & $n$ & $\%$ & $n$ & $\%$ \\
\hline $\begin{array}{l}\text { Men } \\
\text { Women }\end{array}$ & $\begin{array}{r}73 \\
118\end{array}$ & $\begin{array}{l}8.8 \\
6.6\end{array}$ & $\begin{array}{l}282 \\
194\end{array}$ & $\begin{array}{r}13.4 \\
9.6\end{array}$ & $\begin{array}{l}171 \\
252\end{array}$ & $\begin{array}{l}17.9 \\
16.2\end{array}$ & $\begin{array}{l}526 \\
564\end{array}$ & $\begin{array}{l}13.5 \\
10.5\end{array}$ \\
\hline Total & 191 & 7.3 & 476 & 11.5 & 423 & 16.8 & 1090 & 11.8 \\
\hline
\end{tabular}

Table 2 Distribution of under-reporters* according to gender and BMI

-Under-reporters were identified assuming a physical activity level (PAL) of 1.55 
Table 3 Predictors for under-reporting " energy intake

\begin{tabular}{llc}
\hline Variables & Odds ratio & $95 \%$ confidence interval \\
\hline$B M I$ & 1.00 & \\
$\leq 25$ & 1.50 & $1.25-1.80$ \\
$25<\mathrm{BMI} \leq 30$ & 2.32 & $1.92-2.80$ \\
$>30$ & & \\
Gender & 1.0 & \\
Female & 1.41 & $1.23-1.61$ \\
Male & & \\
Educational level & 1.0 & \\
llliterate & 0.60 & $0.50-0.74$ \\
Primary & 0.66 & $0.53-0.83$ \\
Secondary & 0.76 & $0.60-0.96$ \\
University & & \\
Age & 1.0 & \\
$<40$ & 1.36 & $1.09-1.70$ \\
$40-49$ & 1.65 & $1.31-2.08$ \\
$50-59$ & 1.39 & $1.08-1.78$ \\
$60+$ &
\end{tabular}

-Under-reporters were identified assuming a physical activity level (PAL) of 1.55 .

proportional energy intake values from macronutrients when under-reporters are excluded are generally minor, even when they are statistically significant, as is the case with respect to fat and carbohydrates in women. Significant differences for the micronutrient densities were found for potassium, iron, magnesium and nicotinic acid in both genders. It should be noted that these significant differences, are due to higher nutrient/energy ratios for the specific nutrients among under-reporters.

\section{Discussion}

This study indicates underestimation of energy intake by about $12 \%$ of individuals enrolled. Underestimation by a fraction of study participants is unavoidable in all methods of dietary ascertainment, whether these apply to epidemiological studies of individuals in habitual conditions or to metabolic studies which measure energy intake under controlled conditions ${ }^{17,18}$. Previous published studies show the prevalence of under-reporting to vary from low values to almost $50 \%$ among obese individuals ${ }^{19,20,22}$ while in this investigation individuals underestimating energy intake were found to be proportionally fewer than in most other published studies. However, both the method used for determining dietary intake and the cut-off points adopted for the estimation of under-reporting, vary considerably among studies. The only published report using the same method for estimating energy intake (semi-quantitative food frequency questionnaires) and the same cut-off point $(\mathrm{EI} / \mathrm{BMR}$ ratio $=1.14)$ as those used in our study was

Table 4 Effect of under-reporting* on mean nutrient intakes

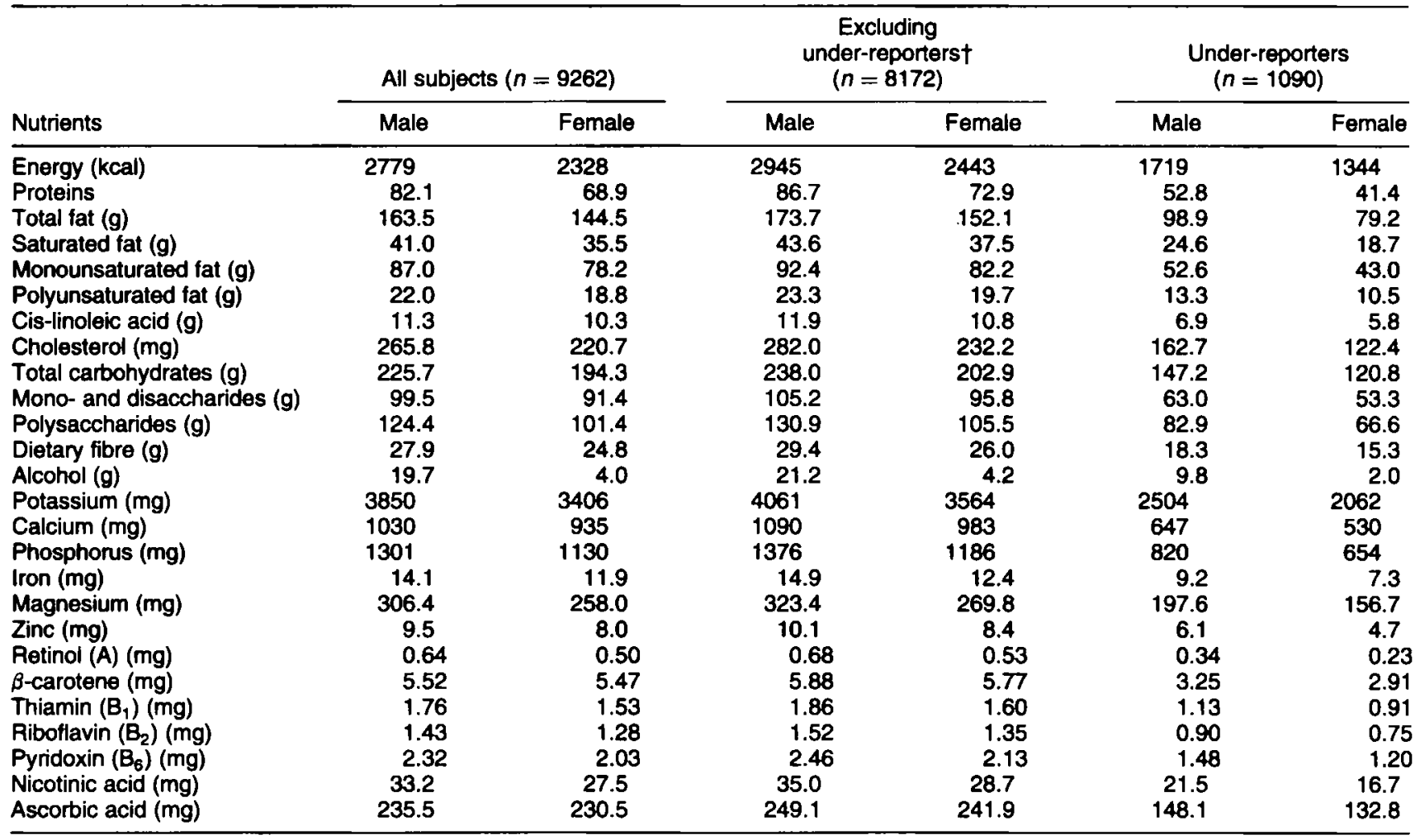

-Under-reporters were identified assuming a physical activity level (PAL) of 1.55.

tWhen under-reporters are excluded, all differences in mean nutrient intakes are statistically significant, except alcohol intake among women. 
Table 5 Effect of under-reporting* on percentage of energy obtained from macronutrients

\begin{tabular}{|c|c|c|c|c|c|c|}
\hline \multirow[b]{2}{*}{ Nutrients } & \multicolumn{2}{|c|}{ All subjects $(n=9262)$} & \multicolumn{2}{|c|}{$\begin{array}{l}\text { Excluding } \\
\text { under-reporters } \\
(n=8172)\end{array}$} & \multicolumn{2}{|c|}{$\begin{array}{l}\text { Under-reporters } \\
\quad(n=1090)\end{array}$} \\
\hline & Male & Female & Male & Female & Male & Female \\
\hline $\begin{array}{l}\text { Total fat } \\
\text { Proteins } \\
\text { Total carbohydrates } \\
\text { Alcohol }\end{array}$ & $\begin{array}{r}52.6 \\
11.8 \\
32.8 \\
4.8\end{array}$ & $\begin{array}{r}55.3 \\
11.9 \\
33.9 \\
1.2\end{array}$ & $\begin{array}{r}52.8 \\
11.8 \\
32.7 \\
4.9\end{array}$ & $\begin{array}{l}55.6 t \\
11.9 \\
33.6 t \\
1.2\end{array}$ & $\begin{array}{r}51.6 \\
12.3 \\
34.4 \\
3.9\end{array}$ & $\begin{array}{r}52.8 \\
12.3 \\
36.2 \\
1.0\end{array}$ \\
\hline
\end{tabular}

-Under-reporters were identified assuming a physical activity level (PAL) of 1.55.

†Statistically significant differences $(P<0.05)$ in mean intakes when under-reporters are excluded.

done in Australia ${ }^{21}$. The proportion of under-reporting in that study was $29 \%$ of all participants.

As indicated, the prevalence of under-reporters depends on the method used for determining dietary intake and the cut-off point adopted for the evaluation of the EI/BMR ratio. The cut-off point of energy intake used in this analysis (1.14*BMR) is relatively low compared to those used in most previous studies. These ranged between $2.10^{*} \mathrm{BMR}$ and $1.06^{*} \mathrm{BMR}^{22}$. The use of a low cut-off point is justified by the fact that participants in the study had low physical activity levels.

The prevalence of under-reporters in this study is related to BMI value. The proportion of overweight participants (BMI >30) who tend to under-report energy intake is more than twice that of normalweight individuals. This finding is in accordance with results of several previous studies ${ }^{21-25}$. An exception is a study by Lissner $e t a l{ }^{26}$ where no relationship was found between under-reporting and adiposity. In our study, the percentage of male under-reporters (13.5\%) is greater than that of female under-reporters (10.5\%). Conflicting results have been obtained in this area of research - some studies have found a larger percentage of under-reporters among women ${ }^{21,22}$ whereas others have found no relationship between the two variables ${ }^{4}$.
Despite the relatively low prevalence of underreporting, it was necessary to investigate its effect on nutrient intake values. As expected, exclusion of underreporters generates mean values that are systematically and significantly higher than those derived from the total number of participants. When the nutrient values are energy-adjusted, however, or are expressed as percentages of energy intake for macronutrients or as nutrient densities for micronutrients, the differences which arise are minimal and generally statistically not significant or marginally significant. For data concerning macronutrients, minor differences were noted among women for energy intake from fat and carbohydrates: proportional intake increased for fat when female under-reporters were excluded, whereas the opposite was found for carbohydrates. Minor changes were also noted in micronutrient densities when under-reporters were excluded. Relatively more evident changes were recorded for potassium, iron, magnesium and nicotinic acid: the values for these nutrients decrease, when under-reporters were excluded, among both women and men.

The interpretation of data concerning under-reporters depends on the objectives of the study. If the prime interest is on estimation of absolute intake of various

Table 6 Effect of under-reporting* on micronutrient densities

\begin{tabular}{|c|c|c|c|c|c|c|}
\hline \multirow{2}{*}{$\begin{array}{l}\text { Micronutrients } \\
\left(\mathrm{mg} \mathrm{MJ}^{-1}\right)\end{array}$} & \multicolumn{2}{|c|}{ All subjects $(n=9262)$} & \multicolumn{2}{|c|}{$\begin{array}{l}\text { Excluding under-reporters } \\
\qquad(n=8172)\end{array}$} & \multicolumn{2}{|c|}{ Under-reporters $(n=1090)$} \\
\hline & Male & Female & Male & Female & Male & Female \\
\hline $\begin{array}{l}\text { Potassium } \\
\text { Calcium }\end{array}$ & $\begin{array}{r}334.1 \\
88.6\end{array}$ & $\begin{array}{r}352.1 \\
95.7\end{array}$ & $\begin{array}{l}331.7 \dagger \\
88.4\end{array}$ & $\begin{array}{c}350.4 \dagger \\
95.9\end{array}$ & $\begin{array}{r}349.3 \\
89.8\end{array}$ & $\begin{array}{r}367.0 \\
94.2\end{array}$ \\
\hline Phosphorus & 112.0 & 116.1 & 111.7 & 116.1 & 113.7 & 116.1 \\
\hline Iron & 1.23 & 1.23 & $1.22 \dagger$ & $1.22 \dagger$ & 1.28 & 1.31 \\
\hline Magnesium & 26.5 & 26.7 & $26.4 \dagger$ & $26.5 \dagger$ & 27.5 & 27.9 \\
\hline Zinc & 0.823 & 0.821 & 0.820 & 0.82 & 0.840 & 0.831 \\
\hline Retinol (A) & 0.053 & 0.050 & 0.054 & 0.510 & 0.047 & 0.041 \\
\hline$\beta$-carotene & 0.472 & 0.551 & 0.475 & 0.555 & 0.451 & 0.515 \\
\hline Thiamin $\left(\mathbf{B}_{1}\right)$ & 0.152 & 0.158 & 0.151 & 0.157 & 0.157 & 0.162 \\
\hline Riboflavin $\left(\mathrm{B}_{2}\right)$ & 0.123 & 0.132 & 0.123 & 0.132 & 0.125 & 0.133 \\
\hline $\begin{array}{l}\text { Pyridoxin }\left(\mathbf{B}_{6}\right) \\
\text { Nicotinic acid }\end{array}$ & $\begin{array}{l}0.201 \\
2.87\end{array}$ & $\begin{array}{l}0.210 \\
2.85\end{array}$ & $\begin{array}{l}0.200 \\
2.86 t\end{array}$ & $\begin{array}{l}0.209 \\
2.83+\end{array}$ & $\begin{array}{l}0.206 \\
2.99\end{array}$ & $\begin{array}{l}0.213 \\
3.01\end{array}$ \\
\hline Ascorbic acid & 20.4 & 23.6 & 20.3 & 23.6 & 22.1 & 23.5 \\
\hline
\end{tabular}

-Under-reporters were identified assuming a physical activity level (PAL) of 1.55.

†Statistically significant differences $(P<0.05)$ in mean intakes when under-reporters are excluded. 
nutrients and accuracy of estimation is of importance, then the exclusion of under-reporters leads to more valid results. If, however, interest is focused on energyadjusted estimates, then the exclusion of underreporters has minimal effect on the results. This last situation usually occurs in many nutritional epidemiological studies where energy intake is considered as a possible confounding factor.

In this analysis a physical activity level of 1.55 was used, as suggested by FAO/WHO/UNU ${ }^{15}$, in order to identify individuals most likely to under-report. Recently, meta-analyses of doubly-labelled water data have generated physical activity values specific for age and gender and have also demonstrated that underreporting is more widespread ${ }^{27-29}$. The more detailed analyses, however, require calculation of physical activity levels for individuals and the relevent data have not yet been validated in the Greek sociocultural context. Nevertheless our findings are qualitatively sound and the implications correct, even if the underreporting is not fully captured through the indicated procedure.

The validation of intake values is usually focused on under-reporters, whereas the possible overestimation is rarely addressed. In the latter situation, the physical activity level of each individual would have to be considered in order to determine relevant 'upper limits' of nutritional intake ${ }^{4,22}$. The problem is complicated, however, because over- and underestimation of physical activity may actually be more extensive than that concerning dietary intakes.

\section{References}

1 Coward WA. The doubly-labelled water $\left({ }^{2} \mathrm{H}_{2}{ }^{18} \mathrm{O}\right)$ method: principles and practice. Proc. Nutr. Soc. 1988; 47: 209-18.

2 Schoeller DA, Bandini LG, Dietz WH. Inaccuracies in selfreported intake identified by comparison with the doublylabelled water method. Can. J. Physiol. Pharmacol. 1990; 68: 941-9.

3 Goldberg GR, Black AE, Jebb SA, Cole TJ, Murgatroyd PR, Coward WA, Prentice AM. Critical evaluation of energy intake data using fundamental principles of energy physiology: 1. Derivation of cut-off values to identify underrecording. Eur. J. Clin. Nutr. 1991; 45: 569-81.

4 Black AE, Goldberg GR, Jebb SA, Livingstone MBE, Cole TJ, Prentice AM. Critical evaluation of energy intake data using fundamental principles of energy physiology: 2. Evaluating the results of published surveys. Eur J Clin Nutr. 1991; 45: 583-99.

5 Haraldsdottir J, Sandstrom B. Detection of underestimated energy intake in young adults. Int. J. Epidemiol. 1994; 23: $577-82$.

6 International Agency for Research on Cancer (IARC). European Prospective Study on Nutrition Cancer and Health. Report on-going activities no. 3. Lyon, France: IARC, 1991.

7 Riboli E. Nutrition and cancer: background and rationale of the European Prospective Investigation into Cancer and Nutrition (EPIC). Ann. Oncol. 1992; 3: 783-91.

8 Trichopoulos D, Tzonou A, Katsouyanni K, Trichopoulou A.
Diet and cancer: methodological complexities and casecontrol studies in Greece. In: Mettlin CJ, Aoki K, eds. Recent Progress in Research on Nutrition and Cancer. New York: Wiley-Liss, 1990; 45-53

9 Willett WC, Sampson L, Stampfer MJ, et al. Reproducibility and validity of a semiquantitative food frequency questionnaire. Am. J. Epidemiol. 1985; 122: 51-65.

10 Rimm EB, Giovannucci EL, Stampfer MJ, Colditz GA, Litin LB, Willett WC. Reproducibility and validity of an expanded self-administered semiquantitative food frequency questionnaire among male health professionals. Am. J. Epidemiol. 1992; 135: 1114-26.

11 Gnardellis C, Trichopoulou A, Katsouyanni K, Polychronopoulos E, Rimm EB, Trichopoulos D. Reproducibility and validity of an extensive semi-quantitative Food Frequency Questionnaire among Greek school teachers. Epidemiology 1994; 6: 74-7.

12 Katsouyanni K, Rimm EB, Gnardellis C, Trichopoulos D, Polychronopoulos E, Trichopoulou A. Reproducibility and relative validity of an extensive semi-quantitative Food Frequency Questionnaire using dietary records and biochemical markers among greek school teachers. Int. J. Epidemiol. 1997; 26(suppl. 1): S118-277.

13 Trichopoulou A. Composition of Greek Foods and Dishes (in Greek and English). Athens: National School of Public Health, 1992.

14 Schofield WN, Schofield C, James WPT. Basal metabolic rate. Hum. Nutr. Clin. Nutr. 1985; 39C (suppl. 1): 1-96.

$15 \mathrm{FAO} / \mathrm{WHO} / \mathrm{UNU}$. Report of a joint expert consultation. Energy and Protein Requirements. WHO Technical Report Series no. 724. Geneva: WHO, 1985.

16 Nelson M, Black AE, Morris JA, Cole TJ. Between- and within-subject variation in nutrient intake from infancy to old age: estimating the numbers of days required to rank dietary intakes with desired precision. Am. J. Clin. Nutr. 1989; 50: 155-67.

17 Hallfrisch JJ, Steele P, Cohen L. Comparison of 7-day diet record with measured food intake of 24 subjects. Nutr. Res. 1982; 2: 263-73.

18 Lissner L, Habicht J, Strupp BJ, Levitsky DA, Haas JD, Roe DA. Body composition and energy intake: do overweight women overeat and under-report. Am. J. Clin. Nutr. 1989; 49: 320-5.

19 Lichtman SW, Pisarska K, Berman ER, et al. Discrepancy between self-reported and actual caloric intake and exercise in obese subjects. N. Engl. J. Med. 1992; 327: 1893-8.

20 Ballard-Barbash R, Graubard I, Krebs-Smith SM, Schatzkin A, Thompson FE. Contribution of dieting to the inverse association between energy intake and body mass index. Eur. J. Clin. Nutr. 1996; 50: 98-106.

21 Smith WT, Webb KI, Heywood PF. The implications of underreporting in dietary studies. Aust.J. Publ. Health 1994; 18: $311-14$.

22 Hirvonen $T$, Mannisto S, Roos E, Pietinen P. Increasing prevalence of underreporting does not necessarily distort dietary surveys. Eur. J. Clin. Nutr. 1997; 51: 297-301.

23 Heitmann BL, Lissner L. Dietary underreporting by obese individuals - is it specific or non-specific? Br. Med. J. 1995; 311: 986-9.

24 Bandini LG, Schoeller DA, Cyr H, Dietz WH. A validation of reported energy intake in obese and non-obese adolescents. Am. J. Clin. Nutr. 1990; 52:421-5.

25 Prentice AM, Black AE, Coward WA, et al. High levels of energy expenditure in obese women. Br. Med.J. 1986; 292 : 983-7.

26 Lissner L, Habicht J-P, Strupp BJ, Levitsky DA, Haas JD, Roe DA. Body composition and energy intake: do overweight women overeat and under-report. Am. J. Clin. Nutr. 1989; 49: 320-5. 
27 Black AE, Coward WA, Cole TJ, Prentice AM. Human energy expenditure in affluent societies: an analysis of 574 doublylabeled water measurements. Eur. J. Clin. Nutr. 1996; 50: $72-92$.

28 Black AE. Physical activity levels from a meta-analysis of doubly labeled water studies for validating energy intake as measured by dietary assessment. Nutr, Rev. 1996; 54: $170-4$.

29 Shetty PS, Henry CJK, Black AE, Prentice AM. Energy requirements of adults: an update on basal metabolic rates (BMRs) and physical activity levels (PALs). Eur. J. Clin. Nutr. 1996; 50 (suppl. 1): S11-S23. 